\title{
Gastric antral vascular ectasia: maintenance treatment with oestrogen-progesterone
}

\author{
S F Moss, P Ghosh, D M Thomas, J E Jackson, J Calam
}

\begin{abstract}
Gastric antral vascular ectasia ('watermelon stomach') is a rare cause of chronic gastrointestinal bleeding and various medical and surgical treatments have been described. We report a patient in whom an oestrogenprogesterone preparation successfully controlled recurrent blood loss.
\end{abstract}

\section{Case report}

A 73 year old woman was referred for investigation of recurrent occult gastrointestinal bleeding. She was first found to have a microcytic anaemia when aged 67 years and was treated with iron replacement without further investigation. She remained on iron and was well until 1989, when she again presented with symptomatic anaemia (haemoglobin $5.4 \mathrm{~g} / \mathrm{dl}$ ) and was admitted to her local hospital.

Investigations confirmed iron deficiency and faeces were persistently positive for occult blood. Coagulation studies were normal and there was no evidence of haemolysis. Urea, electrolytes, and liver function tests were all within normal limits, as were her serum vitamin $B_{12}$ and red cell folate. Upper gastrointestinal endoscopy on three occasions showed appreciable antral erythema; endoscopic biopsy specimens revealed no abnormality. Colonoscopy, a small bowel barium enema, and jejunal mucosal biopsy specimens were all normal. What was thought to be antral gastritis was treated with a variety of drugs including ranitidine, omeprazole, antacids, sucralfate, and tripotassium dicitratobismuthate (DeNol). The patient's gastrointestinal blood loss continued, however, and she became dependent on transfusions, receiving 60 units of blood over the course of a year.

On assessment at Hammersmith Hospital in February 1989 her only symptom was recurrent fatigue when anaemic. She also had thyrotoxicosis and non-insulin dependent diabetes mellitus for which she took carbimazole and tolbutamide respectively. She did not drink alcohol or take non-steroidal anti-inflammatory drugs. On examination she had a goitre but no other abnormal findings. Investigation confirmed iron deficiency with occult blood loss, and showed antibodies to gastric parietal cells, with a titre of 1:160. At gastroscopy a series of longitudinally arrayed red streaks were seen radiating to the pylorus - the typical appearances of antral vascular ectasia ('watermelon stomach'). The

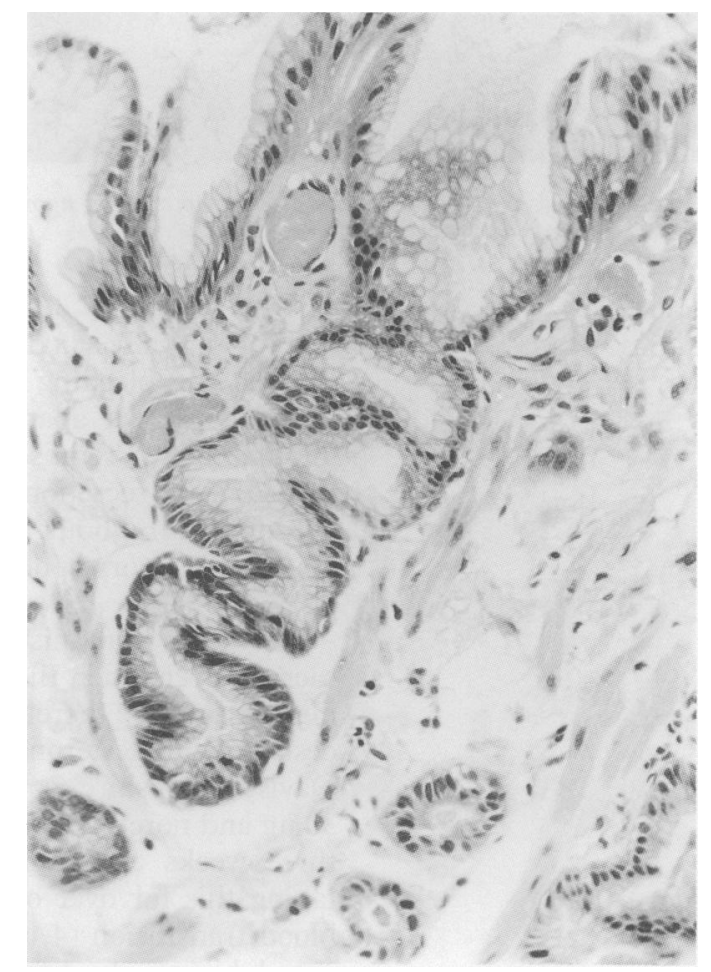

Figure 1: Antral mucosal biopsy specimen showing vertically orientated smooth muscle fibres and capillaries with fibrin thrombi. (Original magnification $\times 130$.)

diagnosis was confirmed histologically: biopsy specimens from the gastric antrum showed dilated blood vessles within the lamina propria (some containing fibrin thrombi) together with prominent vertically orientated muscle fibres (Fig 1). Immunocytochemical staining for gastrin and somatostatin cells and with chromogranin showed normal antral neuroendocrine cell populations, biopsy specimens from the gastric body showed atrophic gastritis.

A technetium labelled red cell scan did not show a source of gastrointestinal blood loss. Inferior and superior mesenteric and coeliac axis angiography was performed. The latter showed considerable hypervascularity of the gastric antrum with early venous drainage, also seen on a selective common hepatic arteriogram (Fig 2). No other abnormalities were seen. Secretory studies disclosed hypochlorhydria with a basal acid output of $0.2 \mathrm{mEq} / \mathrm{hour}$ and a peak acid output after pentagastrin stimulation of $3 \cdot 0$ $\mathrm{mEq} /$ hour (off therapy). The fasting plasma gastrin concentration was correspondingly high (293 $\mathrm{pmol} / \mathrm{ml}$, normal <40). Prednisolone 


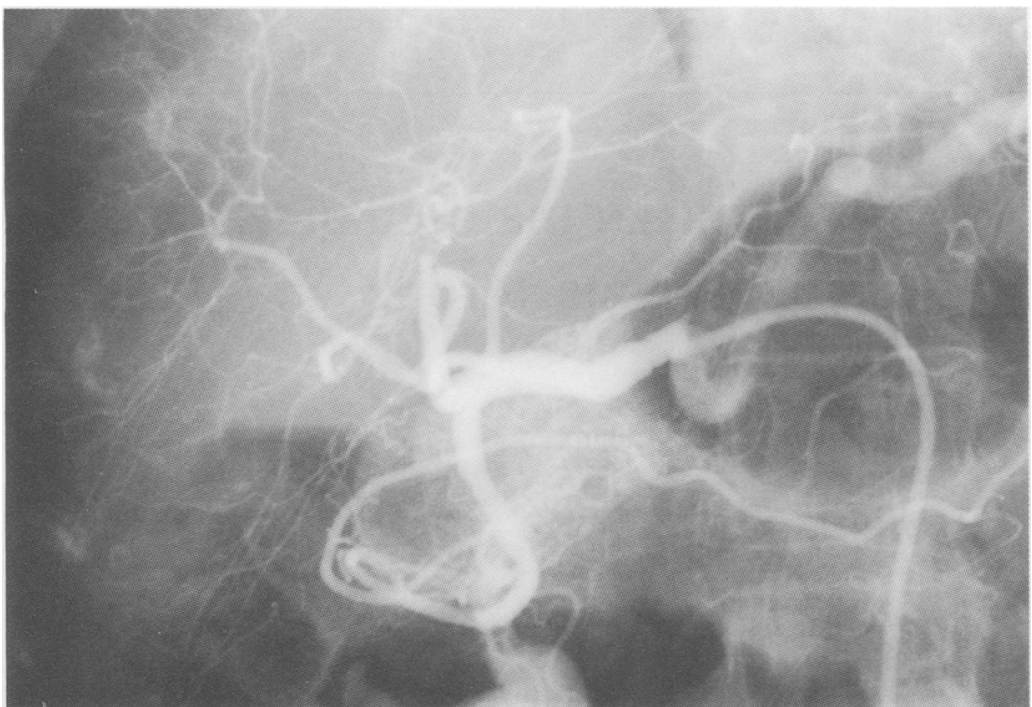

Figure 2: Selective common hepatic arteriogram showing appreciable hypervascularity of the gastric antrum.

therapy, initially at a dose of $30 \mathrm{mg}$, successfully stopped the bleeding (Fig 3) and other drugs were withdrawn apart from carbimazole and tolbutamide. Prednisolone also restored the gastric acid secretion to normal (basal acid output $2 \cdot 7 \mathrm{mEq} /$ hour, peak acid output $14 \mathrm{mEq} /$ hour) with a corresponding fall in gastrin to 70 $\mathrm{pg} / \mathrm{ml}$.

However, prednisolone caused hypergly caemia, even when the dose was reduced to 10 mg per day. We therefore changed to a standard oestrogen-progesterone pill (Loestrin 30, ParkeDavis, Hampshire) containing ethinyloestradiol $30 \mu \mathrm{g}$ and norethisterone $1.5 \mathrm{mg}$ daily taken for three weeks each month. She has now been taking this for over one year. Apart from one blood transfusion (4 units) after an endoscopic antral biopsy she has maintained her haemoglobin concentration on iron alone over this period, showing a considerable reduction in gastrointestinal bleeding (Fig 3).

\section{Discussion}

We have described a patient with gastric antral vascular ectasia causing chronic severe gastrointestinal blood loss which required 60 units of

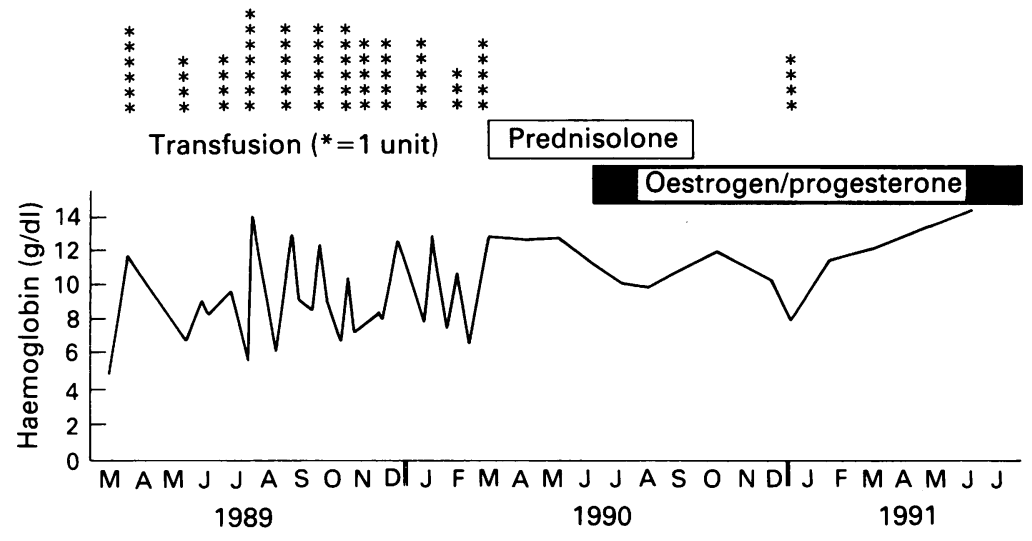

Figure 3: Blood transfusion requirements and serial haemoglobin concentrations, showing the effects of prednisolone and oestrogen-progesterone therapy. transfused blood over one year. Therapy, initially with prednisolone and then with an oestrogen/progesterone pill, has successfully controlled the bleeding.

Gastric antral vascular ectasia (watermelon stomach) was first described in 1953 by Rider et $a l^{1}$ and about 50 further cases have been subsequently reported. The term 'watermelon stomach' was coined by Jabbari in 1984 to describe the endoscopic appearances. ${ }^{2}$ In contrast to the telangiectasia of portal hypertension and Osler-Weber-Rendu there are no lesions in other parts of the stomach. Most of the patients are elderly women in whom a source of occult bleeding is eventually traced to the gastric antrum. The significance of the endoscopic appearances is often overlooked initially. Consequently, these patients tend to be extensively investigated before the diagnosis is reached. Angiography is usually normal but endoscopic biopsy specimens may be diagnostic. ${ }^{3}$

The aetiology of the condition is obscure though the pathological changes found are similar to those of solitary rectal ulcer. The condition is associated with autoimmune conditions, especially atrophic gastritis, demonstrated by achlorhydria, hypochlorhydria, and antiparietal cell antibodies in about a quarter of cases. An increased number of antral neuroendocrine cells has been reported in one case ${ }^{+}$but there was no obvious increase in the number of cells in our patient.

It may be that mucosal atrophy, commonly present in the elderly, exposes the telangiectatic blood vessels to the gastric lumen, making them prone to bleed. Arteriolar changes in the gastric mucosa have been observed in atrophic gastritis and may be of aetiological importance. ${ }^{5}$

A number of treatments have been described for gastric antral vascular ectasia including antrectomy ${ }^{2}$ and therapeutic endoscopy using either laser ${ }^{6}$ or diathermy. ${ }^{7}$ In view of the extensive vascular abnormalities in our patient we did not feel that coagulation treatment was appropriate, owing to the tendency to scar formation. Follow up of patients treated in this way is limited and circumferential scarring leading to stenosis is a risk. As our patient was keen to avoid surgery we opted to treat her with corticosteroids. Three out of four patients with gastric antral vascular ectasia and atrophic gastritis have improved with prednisolone. ${ }^{8-10}$ The rationale for using prednisolone is based upon treating the associated autoimmune atrophic gastritis. Prednisolone has improved gastric mucosal histology and restored gastric acid secretion in some patients with pernicious anaemia," though it is possible that other actions of the corticosteroid may have reduced the bleeding - for example via vasoconstriction ${ }^{12}$ or by an antiangiogenic effect. ${ }^{13}$

Because of the side-effects of prednisolone we elected to use oestrogen-progesterone as a maintenance therapy to control the bleeding. Van Cutsem et al have recently reported the successful treatment of chronic bleeding from gastrointestinal vascular malformations with an oestrogen-progesterone preparation. ${ }^{14}$ In a double blind controlled trial blood requirements in patients with hereditary haemorrhagic 
telangiectasia and colonic angiodysplasia were reduced considerably over a six month period. There were no side effects attributable to the treatment. Our patient has cyclical uterine bleeding but no other adverse effects. In this high risk, elderly population the relative risks from surgery, recurrent blood transfusions, and an oestrogen-progesterone pill are difficult to assess and we feel that the latter is the safest option.

The mechanism of action of the oestrogenprogesterone combination in preventing rebleeding is not clear. It has been shown to be trophic to the nasal mucosa, ${ }^{15}$ possibly via specific receptors, and it may act by a primary effect on haemostasis as changes in coagulation factors may be manipulated by the therapeutic use of sex hormones. ${ }^{16}$ When our patient could no longer tolerate prednisolone we tried this new treatment, which showed considerable success in controlling the chronic blood loss from watermelon stomach.

1 Rider JA, Klotz AP, Kirsner JB. Gastritis with venocapillary ectasia as a source of massive gastric haemorrhage. Gastroenterology 1953; 24: 118-23.

2 Jabbari M, Cherry R, Lough JO, Daly SD, Kinnear DG, Goresky CA. Gastric antral vascular ectasia: The watermelon stomach. Gastroenterology 1984; 87: 1165-7.
3 Gilliam JH, Geisinger MD, Wu WC, Weidner N, Richter JE Endoscopic biopsy is diagnostic in gastric antral vascular ectasia; the watermelon stomach. Dig Dis Sci 1989; 34 $885-8$

4 Lowes JR, Rode J. Neuroendocrine cell proliferations in gastric antral vascular ectasia. Gastroenterology 1989; 97 207-12.

5 Kurumado K, Yamakawa T, Ohara T. Changes in arterioles of the human gastric mucosa with atrophic gastritis. Hepatogastroenterology 1990; 37: 235-8.

6 Gostout CJ, Ahlquist DA, Radford CM, Viggiano TR, Bawyer BA, Balm RK. Endoscopic laser therapy for watermelon stomach. Gastroenterology 1989; 96: 1462-5.

7 Petrini Jl, Johnston JH. Heater probe therapy for vascular ectasia of the antrum [Abstract]. Gastrointest Endosc 1986; 32: $174-5$.

8 Calam J, Walker RJ. Antral vascular lesion, achlorhydria and chronic gastrointestinal blood loss: response to steroids. Dig Dis Sci 1980; 25: 236-9.

9 Rawlinson WD, Barr GD, Lin BPC. Antral vascular ectasiawatermelon stomach. Med F Aust 1986; 144: 709-11.

10 Kruger R, Ryan ME, Dickson KB, Nunez JF. Diffuse gastric ectasia of the gastric antrum. Am $\mathcal{F}$ Gastroenterol 1987; 82 $421-6$.

11 Jeffries GH, Todd JE, Sleisinger MH. The effect of prednisolone on gastric mucosal histology, gastric secretion and vitamin $B_{12}$ absorption in patients with pernicious anaemia. f Clin Invest 1966; 45: 803-12.

12 Marks R, Barlow JW, Funder JW. Steroid induced vasoconstriction: glucocorticoid antagonist studies. $f$ Clin Constriction: glucocorticoid antagon

13 Folkman MD, Ingber DE. Angiostatic steroids: methods of discovery and mechanism of action. Ann Surg 1987; 206: 374-82.

14 Van Cutsem E, Rutgeerts P, Vantrappen G. Treatment of bleeding gastrointestinal vascular malformations with oestrogen-progesterone. Lancet 1990; 335: 953-5.

15 Harrison D. Use of estrogen in treatment of familial hemorrhagic telangiectasia. Laryngoscope 1982; 92: 314-9.

16 Geland JA. Exploiting sex for therapeutic purposes. $N E n g l$ f Med 1983; 308: 1417-9. 